DESBORDES REVISTA DE INVESTIGACIONES ESCUELA DE CIENCIAS SOCIALES, ARTES Y HUMANIDADES — UNAD

\title{
REPRESENTACIONES SOCIALES SOBRE PROYECTO DE VIDA, CONSTRUIDAS POR JÓVENES EN EL MUNICIPIO DE ZIPAQUIRÁ
}

\section{SOCIAL REPRESENTATIONS OF LIFE PROJECT, BUILT BY YOUNG PEOPLE IN THE MUNICIPALITY OF ZIPAQUIRA}

\author{
Sonia Bibiana Rojas Wilches', Leidy Tatiana Rivera Velandia², \\ Flor Ángela Sánchez Forero3, Adriana Yaneth Escandón Sandoval ${ }^{4}$
}

\begin{abstract}
RESUMEN
El artículo presenta los principales resultados del estudio adelantado por el Semillero de Investigación Nómadas de la Escuela de Ciencias Sociales, Artes y Humanidades de la Universidad Nacional Abierta y a Distancia (UNAD), con el objetivo de identificar las representaciones sociales construidas por los jóvenes-, entendiendo como tales, ambos géneros-, del barrio Zipa Vivienda Siglo XXI del municipio de Zipaquirá, a través de una investigación descriptiva haciendo uso de un enfoque metodológico cualitativo, para comprender la configuración de proyectos de vida, imágenes de futuro y la relación que establecen consigo mismos y con su entorno social.

Con el trabajo se evidenció que la manera como los jóvenes actúan en el presente, se encuentra condicionada por su visión del futuro, lo que afecta sus circunstancias actuales. En los hallazgos se aprecia además, que las representaciones sociales de los jóvenes acerca de su proyecto de vida se encuentran en gran medida condicionadas por el entorno social y se construyen a partir de elementos como diferencia de edad, género y nivel de escolaridad.
\end{abstract}

Palabras clave: Entorno social, imágenes de futuro, juventud, proyecto de vida, representaciones sociales.

\section{ABSTRACT}

The article presents the main results of study, developed by the research group "Nomads" belonging to School of Social Sciences, Arts and Humanities, National Open and Distance University (UNAD) aimed to identify the social representations, built by the young people of neighborhood Zipa Vivienda Siglo XXI, through qualitative research to understand the configuration of life projects, images of the future, and the relationship they establish themselves and with their social environment.

\footnotetext{
Sonia Bibiana Rojas Wilches: Socióloga Universidad Santo Tomas, Especialista en Educación, Cultura y Política UNAD cantidadata a Magister en Estudios Culturales Universidad Nacional de Colombia. Tutora de la Escuela de Ciencias Sociales, Artes y Humanidades de la UNAD-CEAD Zipaquira, Colombia.sonia.rojas@unad.edu.co.

2 Leidy Tatiana Rivera Velandia: Estudiante del programa de Psicologia UNAD. tatirive89@hotmail.com.

3 Flor Ángela Sánchez Forero: Estudiante del programa de Psicologia UNAD. angelita591@hotmail.com.

4 Adriana Yaneth Escadón Sandoval: Estudiante del programa de Psicologia UNAD. adriescan28@hotmail.com.
} 
The work made evident that the way to act in the present is conditioned by the vision of the future, thus affecting the current circumstances of young people. In the findings it was also noted that social representations of young people about their life projects, are largely conditioned by the social environment and built from elements such as differences in age, gender and education level.

Key words: images of future, life projects, social environment, social representations, youth.

Recibido: 4 de octubre de 2011 Aceptado: 15 de diciembre de 2011

\section{INTRODUCCIÓN}

A partir de la revisión de investigaciones previas realizadas en Bogotá y Cundinamarca sobre la relación proyecto de vida - juventud, se pudo constatar que este tema ha sido ampliamente abordado por la psicología desde enfoques metodológicos cualitativos y participativos, obteniendo importantes resultados que se convierten en una base para la puesta en marcha de procesos de intervención psicosocial. Si bien muchos de estos estudios privilegian la mirada que los jóvenes tienen frente a su realidad, no se ha determinadolamanera como esa realidad, en tanto entorno social en el que desenvuelven sus prácticas cotidianas, puede determinar las percepciones, opiniones y motivaciones de estos jóvenes con relación a su futuro.

En este sentido, la articulación entre el mundo individual y el social se convierte en un aspecto fundamental a la hora de abordar la construcción de proyectos vitales en jóvenes. Todo ello se debe a que el individuo actúa en un contexto sociocultural específico de normas, valores y formas de interacción que le permiten asumir diferentes roles, los cuales conllevan responsabilidades y compromisos; es así como el proyecto de vida vincula la identidad personal y social, y posibilita el desarrollo a futuro.
Con el estudio se pretendió ampliar el espectro de análisis de la configuración de proyectos de vida juveniles, justamente desde la articulación individuo - entorno social. Para ello, se tomó como referente la teoría de las representaciones sociales, que en palabras de Fonseca, "plantea estas dos dimensiones como interdependientes y relacionadas de manera dialéctica, ante lo cual se contempla que el individuo es constituido por lo social, y constituye lo social al mismo tiempo, a partir de su interacción comunicativa y de producción de sentido sobre el mundo" (2009, p. 46).

El contexto en el que se desarrolló la investigación es el barrio Zipa Vivienda Siglo XXI, ubicado al noroccidente de Zipaquirá, y considerado como uno de los sectores más vulnerables del municipio por cuanto sus habitantes se ven expuestos a problemáticas situacionales y psicosociales como: Hacinamiento, ausencia de espacios ludo-deportivos, vías sin pavimentar, inseguridad, consumo de sustancias psicoactivas, bajo control de la natalidad, conductas delictivas, violencia intrafamiliar y desempleo.

El conocimiento de las estructuras objetivas en las que se desarrollan los jóvenes sujetos del presente estudio, esto es, su contexto comunitario barrial, fue fundamental, ya que estas estructuras definen en gran 
medida las coerciones externas que limitan las interacciones y representaciones sociales que estos jóvenes construyen en sus prácticas cotidianas. También fue importante aproximarse a su subjetividad, con el fin de comprender las formas como desarrollan propuestas de vida particulares. Para lograr esta comprensión, se planteó el siguiente problema a manera de pregunta de investigación: ¿Cuáles son las representaciones sociales construidas por los jóvenes habitantes del barrio Zipa Vivienda Siglo XXI frente a su proyecto de vida y la relación con el entorno social donde llevan a cabo sus prácticas cotidianas?

Como ya se anotó, el estudio tuvo como referente la teoría de las representaciones sociales elaborada ampliamente en el contexto de la psicología social. Serge Moscovici define las representaciones sociales como "una modalidad particular del conocimiento, cuya función es la elaboración de los comportamientos y la comunicación entre los individuos (...) la representación es un corpus organizado de conocimientos y una de las actividades psíquicas gracias a las cuales los hombres hacen inteligible la realidad física y social, se integran en un grupo o en una relación cotidiana de intercambios, liberan los poderes de su imaginación" (1981, p. 18).

De acuerdo con Sandoval (1997), las funcionesquecumplenlasrepresentaciones sociales son cuatro: La comprensión, función que posibilita pensar el mundo y sus relaciones; la valoración, que permite calificar o enjuiciar hechos; la comunicación, a partir de la cual las personas interactúan mediante la creación y recreación de las representaciones sociales; y la actuación, que está condicionada por las representaciones sociales.
La generación de una representación social consiste en dos procesos: El anclaje y la objetivación. En el anclaje el objeto se integra cognitivamente al sistema de pensamiento preexistente. Para seleccionar entre múltiples significados, el sujeto recibe una red de estos, que es otorgada por la sociedad y sus diferentes grupos. La sociedad ofrece al sujeto un margen dentro del cual situar y evaluar un hecho social (Araya, 2002). Por su parte, el proceso de objetivación se presenta en tres fases: Los elementos de un objeto social son descontextualizados de él, recontextualizándose en estructuras previas de los sujetos o grupo en particular (criterios culturales y normativos significativos para el grupo), lo que implica que los elementos seleccionados se organizan en un esquema estructurante; este esquema $\mathrm{o}$ núcleo figurativo es naturalizado, se vuelve "real", no se lo cuestiona y se integra al sentido común. (Jodelet, 1984).

Desde este referente teórico se establecieron unas categorías de análisis, a partir de las cuales se identificaron las representaciones sociales construidas por jóvenes en el Barrio Zipa Vivienda Siglo XXI: Imágenes de futuro, proyecto de vida y entorno social. A continuación se da una breve definición de cada una, con el fin de contextualizar los resultados que más adelante se presentan.

Para el uso concreto de la investigación se asumió como objeto social representado el futuro, identificando las imágenes que los jóvenes crean respecto a este. Con base en la clasificación de las imágenes mentales de Richardson (2005), y en la conceptualización de Seginer (citado en Savio, 2009), se definen las imágenes de futuro como las representaciones mentales que establecen las personas acerca de su 
futuro, que puedenconocersepormedio de la comunicación consciente y expresa. Este es un concepto fundamental para comprender la configuración de proyectos vitales, ya que el modelo de futuro que tiene una persona proporciona fundamentos para establecer objetivos, planificar y fijar compromisos (Bandura, 2001).

El concepto proyecto de vida es definido por D’Ángelo como "la estructura que expresa la apertura de la persona hacia el dominio del futuro, conllevando a decisiones vitales, con perspectivas anticipadas a los acontecimientos futuros en una determinada sociedad" (2000, p. 271). Es también el resultado de modos de enfrentamiento y experimentación de la historia de vida personal en el contexto en el que las actuaciones han tenido lugar, tomando como referente la propia estructura de la realidad en que se ha desplegado la actividad individual (Seve, 1975).

Finalmente, el entorno social "involucra personas, individuos, los cuales tienen esa capacidad innata de relacionarse, poseen el instinto gregario propio de todo ser humano" (Aguilar y Catalán, 2005, p. 2). Los instrumentos necesarios para el desarrollo de actividades en la búsqueda del camino para lograr los objetivos trazados en la ejecución de proyectos de vida los reúne el entorno social; de igual forma, las representaciones sociales constituyen modalidades de pensamiento práctico orientadas hacia la comunicación, la comprensión y el dominio del entorno social, material e ideal.

\section{METODOLOGÍA}

\section{Tipo de investigación}

Se desarrolló una investigación de tipo descriptivo que tiene como preocupación primordial describir situaciones y eventos, y usa criterios sistemáticos que permiten poner de manifiesto la estructura o el comportamiento delosfenómenosenestudio (Tamayo, 2005). Esta investigación se orientó desde un paradigma interpretativo, utilizando un enfoque metodológico cualitativo, en el cual predomina la observación y se considera el contexto y la subjetividad en la experiencia investigativa, conformando una propuesta exploratoria, inductiva y descriptiva (Hoyos, 2000). Se centra en el estudio del significado de las acciones humanas y de la vida social, percepciones, actitudes, conocimientos y sentidos que construyen los sujetos en sus prácticas cotidianas, convirtiéndose, por tanto, en un enfoque ideal para el abordaje de las representaciones sociales.

\section{Participantes}

El barrio Zipa Vivienda Siglo XXI cuenta con una población total de 685 personas cuya edad oscila entre los 0 y los 79 años, de las cuales 208 son jóvenes entre 14 y 26 años (Sistema de identificación de pontenciales beneficiarios de programas sociales, SISBEN, 2010). En la investigación participaron 19 jóvenes (12 mujeres y siete hombres) entre 14 y 26 años de edad, que fueron localizados a través de la técnica de muestreo cualitativo conocida como "bola de nieve", que consiste en la presentación sucesiva de nuevos sujetos a partir de los iniciales. 


\section{Instrumentos y procedimiento}

La investigación inició en junio de 2010 y culminó en abril de 2011 y se desarrolló en tres fases: En la fase de planificación de la investigación se realizó la revisión y el análisis documental de los referentes teóricos e investigaciones previas que sustentaron el trabajo, así como el diseño de los instrumentos propios de cada técnica de investigación. Durante la fase de trabajo de campo, se aplicaron las técnicas para la construcción de información cualitativa como son: la entrevista en profundidad, aplicada a un total de 15 jóvenes; la observación participante, cuyos datos fueron registrados en diarios de campo; y el grupo de discusión, en el que participaron siete jóvenes. En la fase de sistematización de la información se desarrolló un análisis de contenido, siguiendo los pasos propuestos por Bonilla y Rodríguez (1996), los cuales son: 1. Conversión de la información en forma de material escrito; 2. Categorización; 3. Clasificación y ordenación; 4. Descripción de los hallazgos aislados.

\section{RESULTADOS}

Los jóvenes habitantes del Barrio Zipa Vivienda Siglo XXI dieron cuenta en sus relatos del contenido de las representaciones sociales que han construido acerca de sus proyectos de vida, las imágenes de futuro a partir de las cuales orientan sus prácticas presentes y la relación que establecen con su entorno social. Se habla de construcción en la medida en que dichas representaciones resultan, por un lado, de sus experiencias sociales, y por otro, de los procesos colectivos de creación de conocimiento que se generan en la interacción y comunicación social.
A continuación se muestran los resultados obtenidos en cada una de las categorías de análisis planteadas para el desarrollo del trabajo.

\section{Entorno social}

La relación que los jóvenes establecen con su entorno social es un factor que indica su nivel de pertenencia a este, y que le permite de forma común trazar metas y tomar decisiones, de tal manera que los proyectos futuros del joven dejen de ser importantes solo para él y sean significativos para la sociedad en donde se va a realizar como sujeto activo. En esta categoría se indagó, entre otros aspectos, por las actitudes y percepciones que tienen los jóvenes frente a su entorno, la manera como creen que la gente de afuera percibe su barrio y los estereotipos construidos sobre la población juvenil en este contexto específico.

Junto con la información y el campo de representación, la actitud se constituye como una de las tres dimensiones de las representaciones sociales. Consiste en una estructura particular de la orientación en la conducta de las personas, cuya función es dinamizar y regular su acción. La actitud expresa el aspecto más afectivo de la representación, por ser la reacción emocional acerca del objeto o del hecho. Es la orientación global positiva o negativa, favorable o desfavorable de una representación (Araya, 2002).

Al preguntar a los jóvenes cómo se sienten viviendo en su barrio, se encontró que existe una generalizada actitud negativa. En su mayoría, los jóvenes no tienen un sentido de pertenencia al barrio, y por tanto, no esperan ni ven un futuro dentro 
de él y no se comprometen ni promueven un cambio positivo allí. Algunos desean cumplir la mayoría de edad para buscar nuevas alternativas que les permitan alcanzar sus metas y mejorar su calidad de vida, pero fuera del barrio. La falta de sentido de pertenencia hace que tanto jóvenes como adultos resalten y reconozcan las problemáticas del barrio, pero no tomen la iniciativa para generar cambios.

De otra parte, la percepción es un componente del conocimiento que le permite al sujeto interactuar con el mundo objetivo, precisamente al percibirlo. Por esa razón la percepción está ligada al lenguaje y es un elemento básico en la constitución de representaciones sociales. Así, las percepciones están relacionadas con los mecanismos de respuestas sociales y de procesamiento de la información que posee el individuo (Araya, 2002).

En los relatos de los jóvenes se encontró de manera recurrente la percepción de que su barrio es catalogado por actores externos como peligroso, inseguro y lleno de vicios; ellos consideran que el barrio es reconocido en el municipio como un sector marginado, por lo que sienten el rechazo del entorno social más amplio en el que están inmersos, cuestión que puede afectar en gran medida la valoración que hacen de las posibilidades queesteentornoles ofreceparaalcanzarsus metas. Como se puede evidenciar, a través de los procesos de objetivación y anclaje estos jóvenes interiorizan y naturalizan las representaciones sociales negativas que se construyen acerca de su comunidad.

Finalmente, los estereotipos son categorías de atributos específicos de un grupo, que se caracterizan por su rigidez. Los estereotipos son el primer paso en el origen de una representación social; cuando se obtiene información de algo o de alguien, esta se adscribe al grupo o a la situación a que pertenece, es decir, los estereotipos cumplen una función de "economía psíquica" en el proceso de categorización social (Araya, 2002).

Es frecuente que los jóvenes del barrio Zipa Vivienda Siglo XXI sean estereotipados en relación con las problemáticas que viven, como "drogadictos", "ladrones", "ñeros", etc. Esto se pudo evidenciar en los comentarios hechos por personas adultas del barrio en entrevistas informales. De otra parte, son señalados por personas que siendo ajenas a la comunidad, conocen su procedencia. Esto significa que la percepción que se tiene del barrio, afuera en un contexto municipal más amplio, es generalizadamente negativa, motivo que hace que estos jóvenes se sientan rechazados y discriminados por el hecho de vivir allí.

Aquí es importante destacar que estos estereotipos pueden afectar significativamente la constitución de identidades en los jóvenes, pues al desconocer el potencial de cambio y el rol protagónico que podrían desempeñar en su comunidad, se puede reforzar la formación de liderazgos nocivos, que no aportan a la consolidación de un proyecto de vida común dentro del barrio.

\section{Imágenes de futuro}

Los jóvenes del barrio Zipa Vivienda Siglo XXI manifiestan el contenido de sus representaciones sociales acerca de su futuro, suproyección hacia este, la definición de metas a nivel educativo, familiar y laboral, recreado todo ello a través de las imágenes mentales que construyen en el presente. La proyección hacia el futuro se define como la perspectiva que posee cada ser humano en cuanto a su futuro, donde se encuentran implícitas las emociones, 
que pueden llevar a lograr los objetivos trazados, o por el contrario, a encontrar impedimentos para alcanzar los mismos.

De acuerdo con las expresiones de los jóvenes, se pudo concluir que su manera de actuar en el presente se encuentra condicionada por su visión del futuro, afectando de esta forma sus circunstancias actuales. Existen, entonces, diversas opiniones en cuanto a su proyección futura, y sus posiciones varían cuando priorizan diferentes alternativas, entre estas, iniciar una carrera profesional, continuar trabajando para subsistir, o simplemente dejar pasar los días sin ningún tipo de preocupación. No obstante, la imagen que privilegian es la de su desarrollo profesional.

De otra parte, al revisar la caracterización socio-demográfica, fue posible deducir que gran parte de los jóvenes que afirman no tener metas claras a futuro, abandonaron sus estudios sin haber logrado culminar su bachillerato. En contraste con lo anterior, los jóvenes que se hallan estudiando o que ya terminaron su educación básica secundaria, tienen como perspectiva de vida iniciar una carrera profesional, y algunos incluso, piensan especializarse posteriormente.

Por otro lado, surge la diferencia de género en el momento de identificar los propósitos y metas de los jóvenes habitantes del barrio Siglo XXI: Mientras que la mayoría de los hombres centran su interés en iniciar una vida laboral y poder colaborar a sus familias, dejando en un segundo plano su formación profesional, las jóvenes muestran mayor satisfacción al referirse a la educación, y sueñan con terminar sus estudios y ser profesionales.
Las manifestaciones de los jóvenes habitantes del barrio Zipa Vivienda Siglo $\mathrm{XXI}$ en cuanto a la definición de sus metas familiares, demuestran que la mayoría de ellos aún no están interesados en conformar un hogar o tener una vida en pareja, y piensan en obtener un trabajo con el fin de colaborar económicamente a sus familias; así, ante el interrogante acerca de sus metas a nivel familiar, se encontraron muy pocas respuestas.

En la vida de todo ser humano, otro factor de gran relevancia son las metas que se plantea a nivel laboral, ya que estas definen también su futuro y la forma de proyectarse hacia el mañana; al parecer, los jóvenes habitantes del barrio Zipa Vivienda Siglo XXI, en su gran mayoría están interesados en iniciar su etapa laboral, pero se quejan debido a la falta de oportunidades para acceder al trabajo.

\section{Proyecto de vida}

El proyecto de vida es la suma de las aspiraciones, ideales y valores que llevan al desarrollo personal del individuo. La formulación de proyectos de vida en los jóvenes incluye sus recursos personales, entendidos como los medios y cualidades con que cuentan para alcanzar sus fines, así como las acciones que desarrollan, la manera como ocupan su tiempo en el presente para concretar el futuro deseado y la definición de planes de acción para lograr sus metas.

Es fundamental que los sujetos reconozcan claramente los recursos personales con que cuentan para alcanzar los fines propuestos para su futuro. Sin embargo, ante la pregunta que se hizo a los jóvenes del barrio Zipa Vivienda Siglo XXI sobre las cualidades con las que creen contar, que 
les contribuye a su desarrollo personal, se encontró que muchos de ellos no logran definir con claridad dichas cualidades. Quienes respondieron asertivamente se enfocaron en cualidades de tipo social como la amabilidad, el compañerismo y la simpatía, pero es importante puntualizar aquí, hasta qué punto, recursos como estos son suficientes para consolidar su proyecto de vida.

El paso por el sistema escolar es una etapa vital para obtener los propios recursos económicos y la independencia de la familia. Para los jóvenes, la educación alcanza una valoración simbólica, expresada como la posibilidad de "salir adelante y progresar". Influye, sin embargo, la situación actual del país, en la cual la gran mayoría de jóvenes que culminan el bachillerato no logran acceder a la educación superior. Así mismo, el desempleo y las dificultades para independizarse, indican que el sistema escolar no permite una integración de los jóvenes al mercado laboral; la educación pública sigue perdiendo calidad y cobertura, y la falta de oportunidades continúa concentrándose en la población joven.

Existe otro componente que es el uso del tiempo libre. El trabajo y el ocio marcan los tiempos vitales con los que se definen los proyectos de vida de los jóvenes de hoy. Tiene que ver con las diferencias notables que se observan en la manera de concebir el tiempo libre, el ocio y la diversión, según el entorno social en el que se encuentren. Es importante recordar que el proyecto de vida se caracteriza por su carácter anticipatorio, modelador y organizador de las actividades principales del comportamiento del individuo, aspecto que contribuye a delinear los rasgos de su estilo de vida personal (Domínguez, 2007). Por tanto, de acuerdo con los proyectos de vida trazados, se buscó identificar las actividades a las que se dedican los jóvenes actualmente y que apuntan a concretar el futuro deseado.

Al preguntar a los entrevistados (jóvenes y adultos) en qué ocupan su tiempo los jóvenes del barrio, dieron diversas respuestas como el estudio, el trabajo, "hacer nada", “delinquir", "fumar marihuana". Prima, sin embargo, una visión del joven "desocupado", lo que implica que desconoce cómo el desempleo le afecta y le lleva a un permanente trasegar en busca de trabajos ocasionales. De otra parte, los relatos de los jóvenes evidencian que existe un vacío temporal en términos de lo que algunos de ellos están llevando a cabo hoy, y lo que tienen previsto a mediano y largo plazo para alcanzar sus metas e ideales y concretar su proyecto de vida.

\section{DISCUSIÓN DE RESULTADOS}

Un elemento fundamental a la hora de investigar la constitución de representaciones sociales sobre el futuro y los proyectos de vida que de allí se derivan, fue comprender la manera como el entorno social donde los jóvenes sujetos de estudio desarrollan sus prácticas cotidianas, afecta y/o condiciona tales representaciones, las cuales, en esa medida, son elaboradas de manera colectiva y se encuentran asociadas a posiciones sociales específicas, como lo menciona Londoño, et al. (2007). Así, las imágenes de futuro de estos jóvenes, las metas que establecen a corto, mediano y largo plazo y las percepciones y actitudes hacia su contexto barrial, se encuentran asociadas a las condiciones de pobreza y desigualdad en las que se encuentran inmersos. De tal manera, el trabajo corroboró lo planteado por Londoño, et al. (2007) en el sentido de que las representaciones sociales siempre son representaciones compartidas por aquellos 
actores que ocupan posiciones semejantes dentro de la estructura social.

A esto se debe añadir, de acuerdo con lo planteado por Savio (2009), que las imágenes de futuro van acompañadas de un determinado estado afectivo. Las emociones influyen sobre el presente e inciden en el futuro, y es así como diferentes estados de ánimo pueden generar en los jóvenes desesperanza, entusiasmo, confianza en sí mismos, angustia o temor, llevándolos de esta forma a iniciar su proyección futura, que se gesta desde edades tempranas y solo se estructura, a nivel de formaciones motivacionales complejas, en la juventud, expresándose en los ideales y la concepción del mundo.

Estos ideales se conciben entonces como la imagen cognitiva-afectiva de lo que el sujeto desea ser, y constituyen una de las formaciones más significativas de la etapa juvenil, cuando adquieren un carácter generalizado, ya que el sujeto se convierte en el centro de su ideal, desempeñando esta formación un importante papel en el proceso de su auto-perfeccionamiento, de acuerdo con lo planteado por autores como González (1983), Bozhovich (1976) y Kon (1990).

De esta manera, en los jóvenes estudiados predomina el ideal generalizado afectivo o activo, que se basa en sus vivencias y experiencias y en la elaboración activa de su contenido, fundamentado en sus principales aspiraciones y necesidades, como lo menciona González (1983). Según este autor, este tipo de ideal presenta una estructura con contenidos elaborados, donde se aprecia un profundo trabajo de abstracción y de análisis de las cualidades seleccionadas, las que se revisten de una fuerza afectivoemocional capaz de impulsar la conducta del sujeto y están relacionadas con la vida cotidiana del sujeto o por lo menos están al alcance de este. No obstante, es importante destacar que en los relatos de algunos jóvenes sujetos de estudio aparecen los ideales de tipo generalizado formal o pasivo, de poca efectividad en la regulación de la conducta, pues "existe cierta elaboración en su estructura; sin embargo, carece de fuerza afectiva, carece de contenido emocional capaz de guiar al sujeto hacia las aspiraciones y valores expresados en el ideal" (Guerra, 1988, p. 1).

En ese sentido, al igual que lo evidenciaron Toro y Ortegón (2002) en su estudio "Jóvenes: Construcción de proyectos vitales, una opción para emprender" realizado en la ciudad de Bogotá, se encontró en algunos de los jóvenes del barrio Zipa Vivienda Siglo XXI un vacío temporal en términos de lo que están llevando a cabo hoy y lo que tienen previsto a mediano y largo plazo para alcanzar sus ideales. Al carecer de fuerza afectiva, no logran desarrollar acciones concretas en el presente que les permita alcanzar sus metas a futuro. Esto quizá se deba en gran medida a la desesperanza que se lee en el contexto barrial, por la situación de pobreza y falta de oportunidades educativas y laborales.

El contexto o entorno social, en tanto estructura objetiva en la que se configuran condiciones desiguales de clase, género y edad, influye en la formulación de imágenes mentales y representaciones sociales hacia el futuro, afectando la configuración de proyectos de vida. Esto fue evidenciado por Diez (2009), en la investigación "Género, trabajo y proyectos de vida: Rarezas de jóvenes empacadores/as en Almacenes Éxito", quien plantea que en un marco de flexibilización y precarización laboral, la posibilidad de vivir una moratoria social se reduce de acuerdo con las diferencias de clase y de género, siendo las mujeres 
las que menor posibilidad tienen de lograr una movilidad social. No obstante, en el estudio adelantado en el barrio Zipa Vivienda Siglo XXI se pudo llegar a una conclusión diferente, pues en este contexto son los hombres quienes en su mayoría ven necesaria su pronta inserción en el mundo laboral, lo que significa una menor posibilidad de vivir una moratoria social, en contraste con las mujeres, que se plantean la continuación de sus estudios como una meta a corto plazo.

\section{CONCLUSIONES}

En este trabajo se realizó un acercamiento directo a la realidad de los jóvenes habitantes del barrio Zipa Vivienda Siglo $X X I$, desde sus representaciones sociales y la forma como construyen sus proyectos de vida. Una de las restricciones que tiene el proyecto para poder ser expandido o replicado en otro entorno social o para generalizar sus resultados, es que se realizó con sujetos muy concretos que hacen parte de una comunidad específica, y las representaciones sociales cambian de un contexto a otro, ya que las personas nacen en un entorno social simbólico y dan por supuesto su entorno natural y físico.

El análisis de las representaciones sociales permitió conocer el papel que los jóvenes juegan en su contexto barrial, sus percepciones y opiniones sobre la realidad de su comunidad, su sentir frente a las necesidades y problemáticas, y plantear posibles soluciones hacia un proyecto de vida comunitario. En el trabajo de campo se pudo evidenciar que el entorno social influye en las proyecciones futuras de los jóvenes, ya que a partir de las representaciones que ellos construyen frente a este entorno, orientan sus prácticas cotidianas, encaminadas -en mayor o menor medida- a la concreción de sus proyectos de vida.
De igual manera, se pudo identificar que este entorno social barrial es para cada uno de los jóvenes su realidad inmediata, que comparte y vive con los demás. Las costumbres, problemáticas, intereses y opiniones, son comunes para el grupo de personas que forman parte de esta comunidad y generan sentido de pertenencia. Cada joven vive el barrio como parte de su cotidianidad, evaluando constantemente las posibilidades que este entorno le brinda para su desarrollo y realización futura.

Con las herramientas que poseen hoy, los jóvenes ven limitadas sus opciones de formación y oportunidades laborales. Tienen en cuenta sus recursos económicos, estatus social, relaciones con personas que no pertenecen al barrio, y sienten menos oportunidades debido a los estereotipos y señalamientos de los que ellos y los demás habitantes del barrio han sido objeto. Sin embargo, aunque ven limitadas sus posibilidades de desarrollo, tienen momentos de altas aspiraciones que son alimentadas por sueños y deseos de superación.

También resulta importante resaltar que no es posible considerar un proyecto de vida como "realista", cuando la persona que lo elabora no tiene en cuenta sus verdaderas capacidades y habilidades, ya que ese conjunto de aspiraciones es muy superior a lo que realmente puede realizar. Para estos jóvenes es aún difícil identificar los recursos personales y sociales con que cuentan para alcanzar sus metas.

Por lo anterior, en el desarrollo de cualquier proceso de intervención se deben sopesar, por una parte, las capacidades y habilidades que poseen los jóvenes para el logro de sus objetivos y el carácter movilizador de las necesidades involucradas en la consecución 
de estos fines, y, por otra, las posibilidades reales y las oportunidades que brinda el medio externo. De ahí que el trabajo deba fundamentarse en un proceso formativo a través del cual los jóvenes logren reconocer sus recursos personales y encaminarlos hacia la consecución de sus metas.

\section{REFERENCIAS}

Aguilar, I. y Catalán, A. (2005). Influencia del entorno social en el desarrollo de las capacidades de los o las adolescentes. Recuperado de http://medicina.uach. cl/saludpublica/diplomado/contenido/ trabajos/1/Osorno\%202005/Influencia del_entorno_social_en_el_desarrollo_ de_los_adolescentes.pdf.

Araya, S. (2002). Las representaciones sociales: Ejes teóricos para su discusión. Cuaderno de Ciencias Sociales 127. Recuperado de http://www.flacso. or.cr/fileadmin/documentos/FLACSO/ Cuaderno127.pdf.

Bandura, A. (2001). Social cognitive theory: An agentic perspective. Annual Review of Psychology, 52, 1-26. Stanford, CA, EE. UU.

Bonilla, E. y Rodríguez, P.(1996). Más allá del dilema de los métodos: La investigación en ciencias sociales. Bogotá, Colombia: Ediciones Uniandes.

Bozhovich, L. I. (1976). La personalidad y su formación en la edad infantil. La Habana, Cuba: Pueblo y educación.

D’Angelo, O.(2000). Proyecto de Vida como categoría básica de interpretación de la identidad individual y social. Revista Cubana de Psicología, 17 (3), 270-275. La Habana, Cuba.
Diez, D. (2009). Género, Trabajo y Proyectos de vida: Rarezas de jóvenes empacadores/ as en Almacenes Éxito. Tesis de grado, Magíster en Estudios de Género, Universidad Nacional de Colombia, Bogotá, Colombia.

Domínguez, L. (2007). Proyecto de vida y valores: Condiciones de la personalidad madura y saludable. Boletín Electrónico de Investigación de la Asociación Oaxaqueña de Psicología, 3 (1), 44-58. Oaxaca, México.

Fonseca, A. (2009). Representaciones sociales del VIH/Sida en jóvenes con y sin VIH en la ciudad de Bogotá D.C.: Aportes para la comprensión de sus significados y prácticas. Tesis de grado, Maestría en Psicología, Universidad Nacional de Colombia, Bogotá, Colombia.

González R. F. (1983). Motivación moral en adolescentes y jóvenes. La Habana, Cuba: Editorial Científico Técnica.

Guerra, R. (1988). La formación de ideales morales a través del cine. Revista Cubana de Psicología, 5 (2). Recuperado de http://pepsic.bvsalud.org/scielo. php?script=sci_arttext $\&$ pid=S025743221988000200009 .

Hoyos, C. (2000). Un modelo para la investigación documental. Bogotá, Colombia: Señal editorial.

Jodelet. D. (1984). La representación social: Fenómenos, conceptos y teoría. En Moscovici, S. (Comp.), Psicología social II. Pensamiento y vida social. Psicología social y problemas sociales (pp. 469494). Barcelona, España: Paidós. 
Kon, I. S. (1990). Psicología de la Edad Juvenil. La Habana, Cuba: Editorial Pueblo y Educación.

Londoño, S., Patiño, C., Cano, V. y Arias, F. (2007). Representaciones sociales de los jóvenes de la ciudad de Medellín sobre el consumo de sustancias psicoactivas en relación con sus escenarios. Informes Psicológicos, 9, Ene-Dic, 11-40. Medellín, Colombia.

Moscovici, S.(1981). On Social Representation. En J. P. Forgas (Comp.), Social cognition. Perspectives in everyday life. Londres, Inglaterra: Academic Press.

Richardson, J. (2005). Imágenes mentales. Madrid, España: Machado Libros.

Sandoval, C. (1997). Sueños y sudores en la vida cotidiana de trabajadores y trabajadoras de la maquilay la construcción. San José, Costa Rica: Editorial de la Universidad de Costa Rica.

Savio, S. (2009). Imágenes de futuro como proyección hacia el futuro: Elemento clave para el estudio de la calidad de vida. Hologramática, 1 (10), 59-74. Recuperado de http://www.cienciared. com.ar/ra/usr/3/590/hologramatica_n10_ volipp59_74.pdf.

Seve, L. (1975). Marxismo y teoría de la personalidad. Buenos Aires, Argentina: Amorrortu.

Sistema de identificación de pontenciales beneficiarios de porgramas sociales, SISBEN.(2010). Estudios socio-económico de la población del barrio Zipa Vivienda siglo XXI. Manuscrito no publicado. Zipaquira, Colombia.

Tamayo y Tamayo, M. (2005). El proceso de la investigación científica. Ciudad de México, México: Limusa.

Toro, J. y Ortegón, A. (2002). Jóvenes: Construcción de proyectos vitales. Una opción para emprender. Bogotá, Colombia: Centro de Investigaciones Escuela de Administración de Negocios. 